\title{
Parenchymal Splenic Metastasis from Ovarian Cancer: A Report of Two Cases and Literature Review
}

\author{
Mohammad Zuhdy ${ }^{1}$, Khaled Gaballa², Omar Hamdy ${ }^{3}$, Reham Alghandour ${ }^{4}$, Mohamed G Elmadawy ${ }^{5}$, Yasmin N Laimon ${ }^{6}$, \\ Gehad A Saleh ${ }^{7}$, Mahmoud M Saleh ${ }^{8}$, Amr Hosam $^{9}$
}

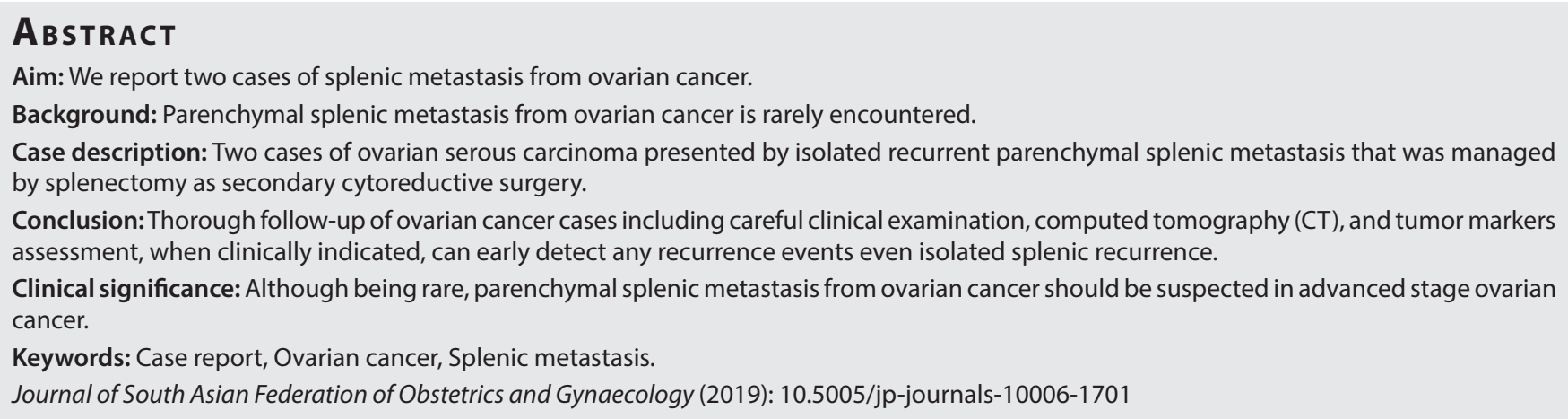

\section{BACKGROUND}

Worldwide, ovarian cancer accounts for $3.4 \%$ of newly diagnosed cancer cases and $4.4 \%$ of cancer-related mortality among females. ${ }^{1}$ It spreads mainly through peritoneal dissemination, hematogenous, or lymphatic routes, and is optimally managed by cytoreductive surgery. ${ }^{2}$ Splenic metastasis from malignant tumors is extremely rare ranging from $2.3 \%$ to $7.1 \%$ in autopsy studies, and a reported incidence of $1.3 \%$ in splenectomy studies. ${ }^{3,4}$ To the best of our knowledge, approximately 24 cases of isolated parenchymal splenic metastasis from ovarian cancer were reported in English-based literature.

\section{Case Description}

\section{Case 1}

A case of 53-year-old woman without relevant medical history was referred to our center. She had history of subtotal hysterectomy and bilateral salpingo-oophorectomy in 2012 with a postoperative pathology report revealing bilateral high-grade papillary serous ovarian carcinoma with infiltration of the fallopian tubes, for which she received eight cycles of taxol/carboplatin regimen till October 2013. Unfortunately, the patient lost follow-up till May 2017 when she developed postcoital bleeding. Pelvic magnetic resonance imaging (MRI) revealed a small uterine stump lesion less than $2 \mathrm{~cm}$, the punch biopsy from it revealed nonkeratinizing squamous cell carcinoma (Fig. 1A). Radiological evaluation of the chest and abdomen by $\mathrm{CT}$ revealed a complex cystic lower pole splenic focal lesion of $5 \times 7 \mathrm{~cm}$ in diameter mostly metastatic with enlarged hilar lymph nodes encasing the splenic artery (Fig. 2). The decision of our multidisciplinary team (MDT) was neoadjuvant chemotherapy where she received further four cycles of the same regimen and then she was referred back for surgery. She was planned for surgery in October 2018 where she underwent splenectomy, omentectomy, and excision of cervical stump. Postoperative pathology report revealed infiltration of the splenic tissue by malignant tumoral proliferation
1-3,5,8,9 Department of Surgical Oncology, Oncology Center, Mansoura University, Mansoura, Egypt

${ }^{4}$ Department of Medical Oncology, Oncology Center, Mansoura University, Mansoura, Egypt

${ }^{6}$ Department of Pathology, Faculty of Medicine, Mansoura University, Mansoura, Egypt

${ }^{7}$ Department of Radiology, Mansoura University Hospitals, Mansoura, Egypt

Corresponding Author: Mohammad Zuhdy, Department of Surgical Oncology, Oncology Center, Mansoura University, Mansoura, Egypt, Phone: +20 1068683363, e-mail: mzuhdy@mans.edu.eg

How to cite this article: Zuhdy M, Gaballa K, Hamdy $O$, et al. Parenchymal Splenic Metastasis from Ovarian Cancer: A Report of Two Cases and Literature Review. J South Asian Feder Obst Gynae 2019; 11(4):273-277.

Source of support: Nil

Conflict of interest: None

of solid sheets of malignant epithelial cells with high-grade atypia, pleomorphism, increased nucleo-cytoplasmic ratio, eosinophilic cytoplasm, vesicular nuclei, and occasional mitotic figures, with an infiltration of 2 out of 10 splenic hilar lymph nodes. Positive cytoplasmic staining for immune histochemical stain (cytokeratin) CK and positive nuclear staining for Wilms tumor 1 (WT-1) confirming the diagnosis of metastatic ovarian serous carcinoma (Fig. 3), while uterine stump showed no residual tumor cells with complete response to previous treatment (Figs $1 \mathrm{~B}$ and $\mathrm{C}$ ). Afterward, the patient received further four cycles of taxol/carboplatin regimen as an adjuvant therapy with no remarkable events till writing this article.

\section{Case 2}

A 72-year-old woman who had history of subtotal hysterectomy without an available postoperative pathology report outside our 

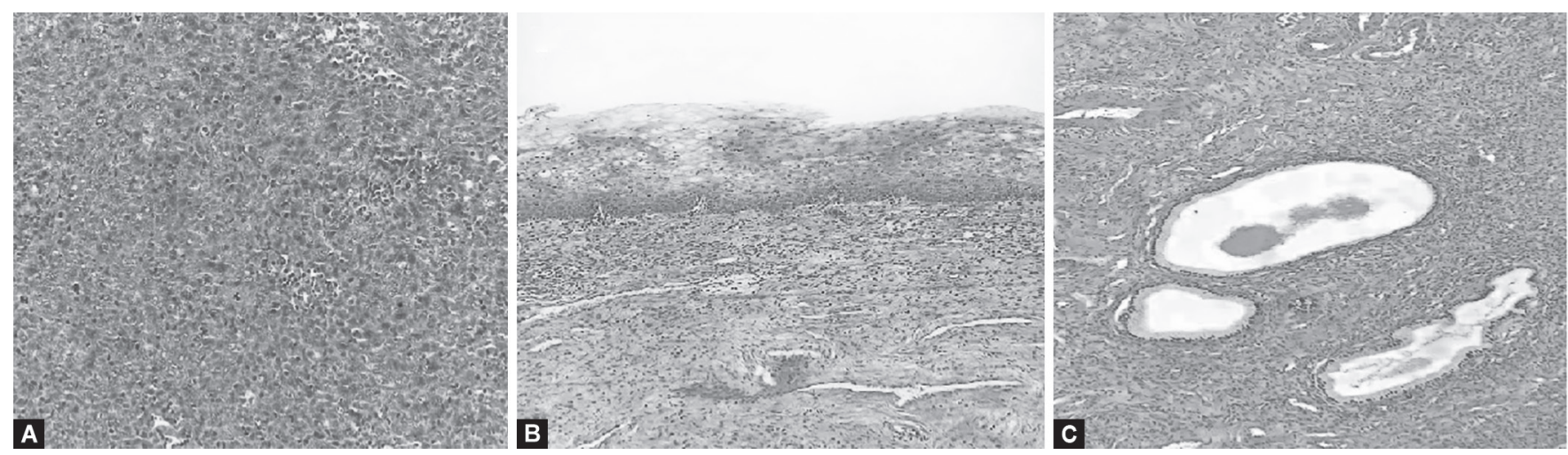

Figs $1 \mathrm{~A}$ to C: (A) Nonkeratinizing squamous cell carcinoma of cervix formed of sheets of neoplastic squamous cells with abundant cytoplasm, nuclear pleomorphism, frequent atypical mitotic figures, and no detected keratinization $(\mathrm{H} \& \mathrm{E}, \times 400)$; (B) Nonkeratinizing stratified squamous epithelium and elastic stroma of ectocervix free from tumor tissue $(\mathrm{H} \& \mathrm{E} \times 200)$; (C) Free endocervical glands from tumor tissue $(\mathrm{H} \& \mathrm{E}, \times 200)$
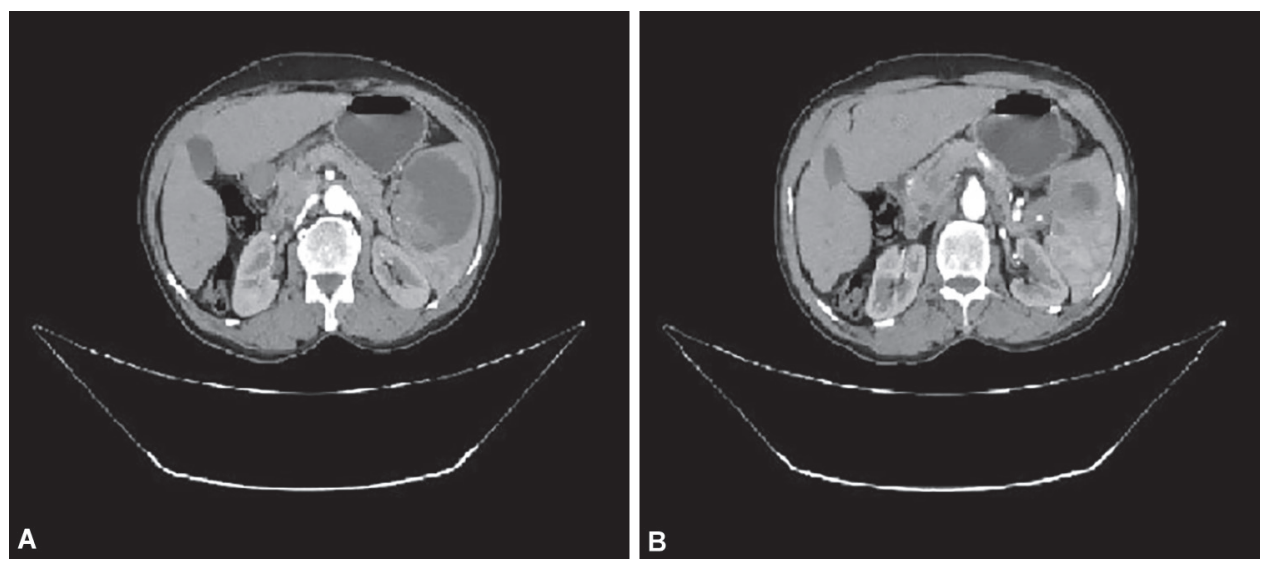

Figs $2 \mathrm{~A}$ and B: Postcontrast computed tomography $(\mathrm{CT})$ abdomen axial images: (A) Large splenic lower pole complex soft tissue mass measures $5 \times 6 \mathrm{~cm}$, no extracapsular extension; (B) Splenic hilar nodal deposit encasing the splenic artery

center in 2011 sought medical advice at our clinic in 2014 because of a radiologically malignant looking bilateral adnexal masses that measured $8 \times 10.5 \times 15 \mathrm{~cm}$ and $6 \times 6.5 \times 7 \mathrm{~cm}$. Metastatic workup revealed a suspicious omental cake of $5 \times 6 \mathrm{~cm}$ and revealed an elevated cancer antigen (CA) $125=231$ (reference up to 35). The decision of our MDT was surgical exploration aiming at optimal cytoreduction. The patient underwent bilateral salpingooophorectomy, infracolic omentectomy, excision of uterine stump, iliac and paraortic lymphadenectomy, and peritoneal biopsy. Postoperative pathology revealed moderately differentiated papillary serous cystadenocarcinoma with infiltrated omentum (International Federation of Gynecology and Obstetrics (FIGO) stage IIIc). The patient then received six cycles of taxol/carboplatin regimen then she was subjected to follow-up. In July 2017, a routine follow-up of CT revealed a splenic complex cystic lesion of $3 \times 4 \mathrm{~cm}$ with a gastrosplenic peritoneal deposit of $2.5 \times 4 \mathrm{~cm}$ (Fig. 4). CA 125 was reevaluated, and it was within normal range, so ultrasoundguided fine needle aspiration cytology (FNAC) was requested and cytological report revealed malignant smear of papillary adenocarcinoma. Multidisciplinary discussion recommended reexploration aiming for a secondary cytoreduction. Exploration was performed on October 2017 and no evidence of tumor recurrence was found other than splenic lesions, so splenectomy was done. Pathology report revealed infiltration of splenic tissue by papillary structures with fibrovascular core lined by malignant cells with hyperchromatism, increased nucleocytoplasmic ration, pleomorphism, vesicular nuclei, prominent nucleoli and psammoma bodies, and immune histochemical staining was positive for WT-1 and P53, and negative to P-16 confirming the diagnosis of metastatic papillary serous ovarian carcinoma (Fig. 5). The patient then received two cycles of Gemzar/cisplatin and is now on follow-up with no evidence of recurrence till last follow-up visit in March 2019.

\section{Discussion}

Ovarian cancer is a common gynecological malignancy that presents in an advanced stage in more than $80 \%$ of the patients. ${ }^{5}$ Cytoreductive surgery is considered the cornerstone in management of ovarian cancer aiming at prolongation of overall survival rates and obtaining sound quality of life. ${ }^{6}$

Splenic metastasis is rare, and it had been reported more commonly with breast, lung, colorectal carcinomas, and melanoma. ${ }^{7}$ Parenchymal splenic metastasis from ovarian cancer is rare accounting for $2-3 \%$ of cases. ${ }^{8}$ Splenic capsular involvement secondary to peritoneal seedling is much more encountered. ${ }^{9}$

Isolated splenic metastasis from ovarian cancer is a rare presentation. To the best of our knowledge, 24 cases of isolated splenic metastasis were reported in English-based literature (Table 1). It is frequently found as a part of widespread disease metastasis rather than solitary splenic involvement. ${ }^{10}$ In contrast, 

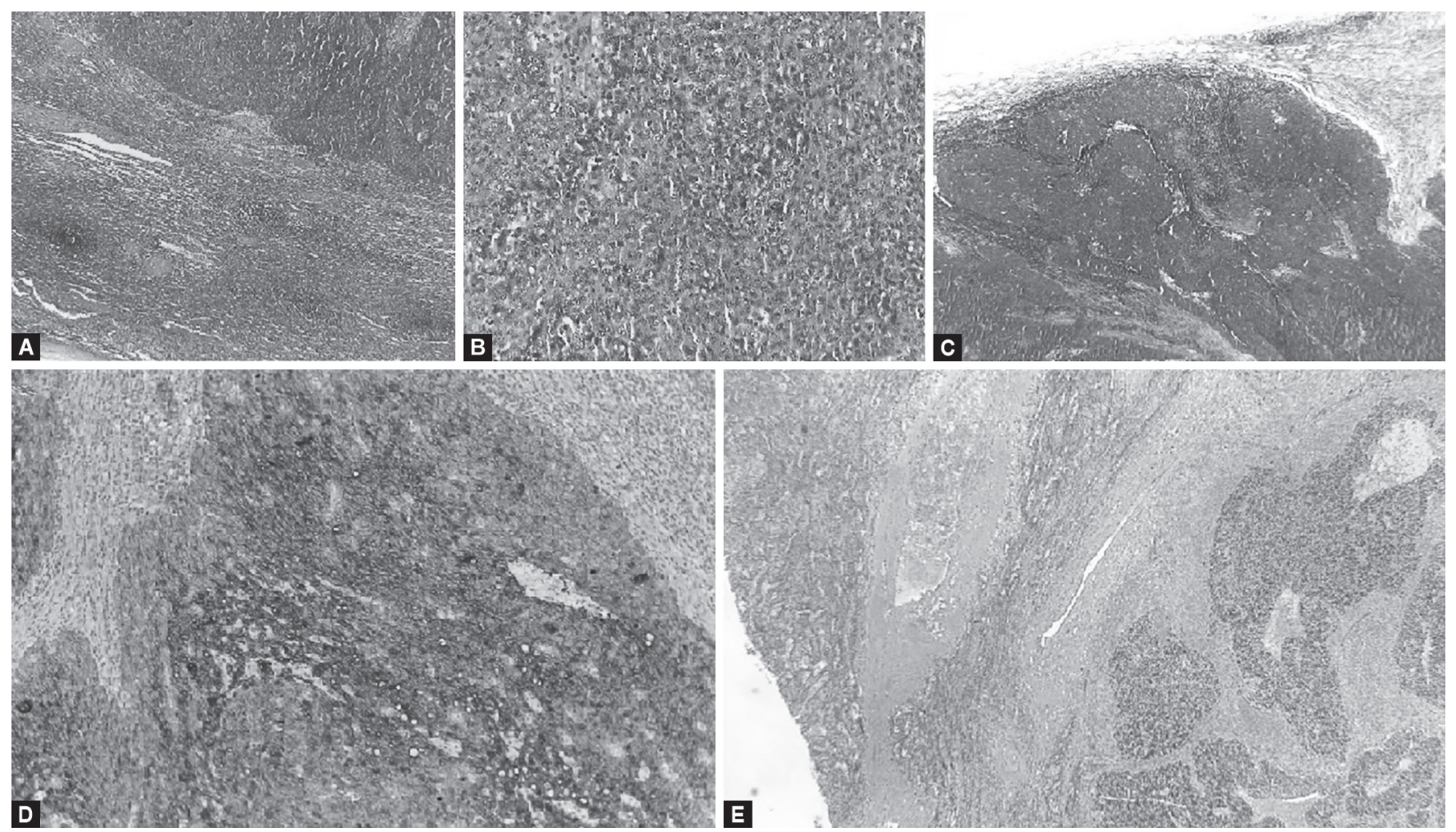

Figs 3A to E: (A) Splenic tissue showing infiltration by solid sheets of high-grade serous ovarian carcinoma (H\&E, $\times 40)$; (B) Sheets of atypical epithelial cells exhibiting marked nuclear atypia, pleomorphism, atypical mitotic figure, and prominent nucleoli (H\&E, $\times 400)$; (C) Splenic hilar lymph node showing malignant deposits of high-grade serous ovarian carcinoma (H\&E, $\times 100)$; (D) The tumor cells show strong diffuse cytoplasmic staining for cytokeratin ( $D A B, \times 200)$; $(E)$ The tumor cells show diffuse nuclear staining for Wilms tumor 1 of metastatic high-grade ovarian serous carcinoma in the spleen $(D A B, \times 200)$
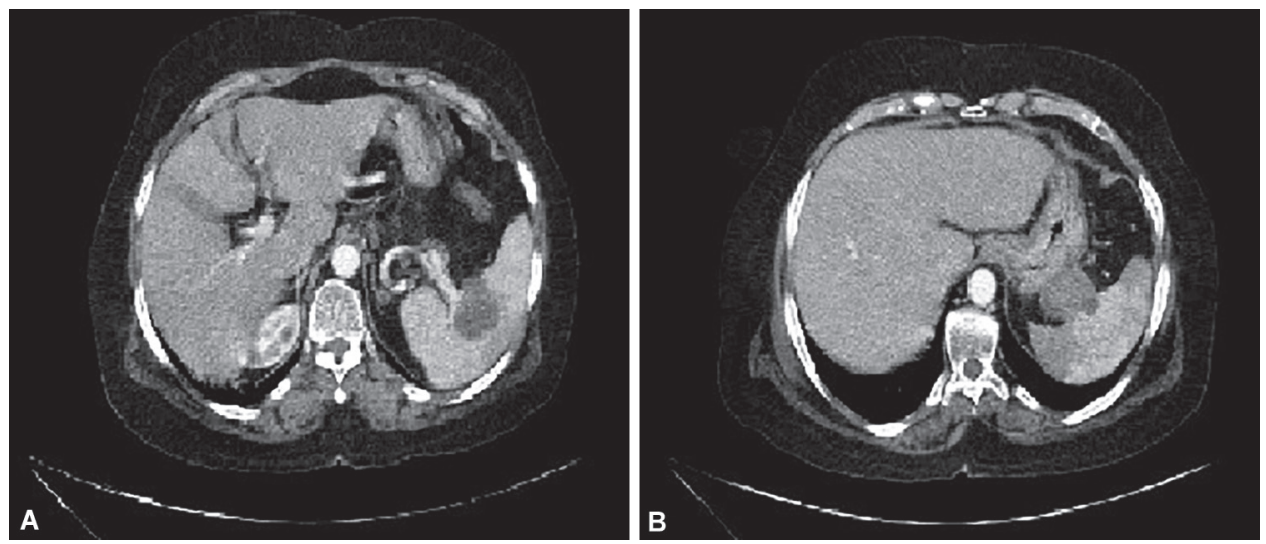

Figs 4A and B: Postcontrast CT abdomen axial images: (A) Parenchymal splenic soft tissue mass measures $3 \times 4 \mathrm{~cm}$, and it is seen abutting the splenic vessels without invasion; (B) Gastrosplenic peritoneal deposit infiltrating the spleen, and it measures $2.5 \times 4 \mathrm{~cm}$

ovarian cancer cases with capsular splenic deposits represented $19-52 \%$ of epithelial ovarian cancer cases at autopsy. ${ }^{11}$

This rare presentation could be explained by several mechanisms including the rhythmic contractions of the splenic capsule, paucity of afferent lymphatics to the spleen, sharp splenic artery angle when originating from the celiac artery, and the antitumor effect of the splenic microenvironment against tumor cells due to the presence of large number of immune cells. ${ }^{12}$ In our first case, there was no evidence of widespread metastasis, and splenic metastasis was the only pattern of recurrence which supports the possibility of hematogenous route of spread.

Thanks to the ovarian cancer surveillance program and the routine use of medical imaging and tumor markers evaluation, the diagnosis of splenic metastasis had increased..$^{12}$ Splenectomy as a part of or the sole entity of optimal cytoreductive surgery is an ideal option for management of splenic metastasis from ovarian cancer either in primary of recurrent setting. ${ }^{13}$ 

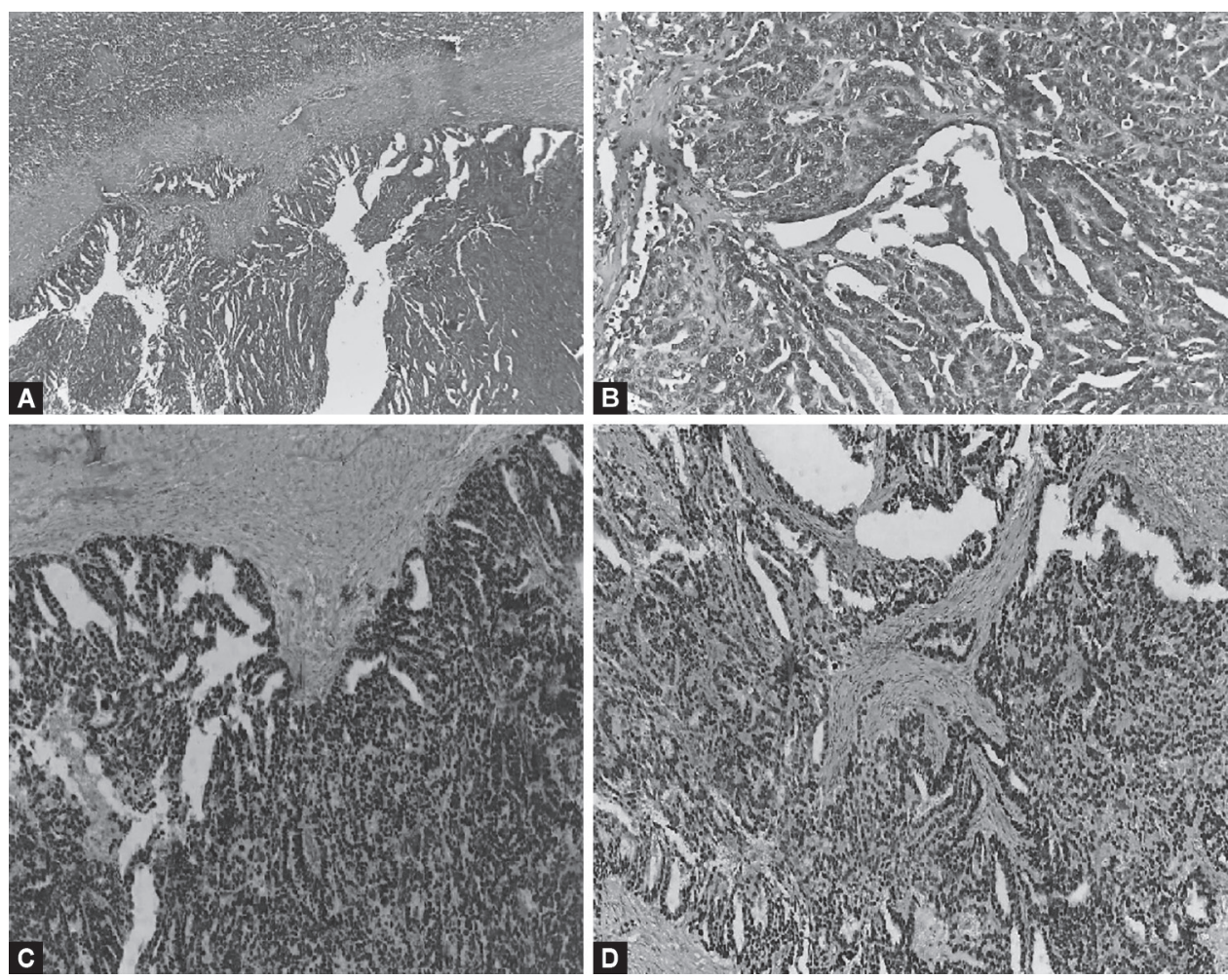

Figs 5A to D: (A) Splenic tissue infiltrated by metastatic papillary serous ovarian carcinoma formed of complex papillary structures with thin fibrovascular cores and covered by atypical cells showing nuclear stratification ( $\mathrm{H} \& \mathrm{E}, \times 40)$; (B) Thin fibrovascular cores lined by atypical epithelial cells exhibiting nuclear pleomorphism, hyperchromasia, and prominent nucleoli $(\mathrm{H} \& \mathrm{E}, \times 200)$; (C) Strong diffuse nuclear positivity for Wilms tumor 1 of metastatic papillary serous ovarian carcinoma in the spleen $(D A B, \times 200)$; (D) Diffuse positive nuclear staining of the tumor cells for P53 (DAB, $\times 200)$

Table 1: Brief literature review of previously reported parenchymal splenic metastasis from ovarian cancer

\begin{tabular}{|c|c|c|c|c|c|}
\hline Author/year & Age & Type/stage & Presentation & Follow-up & Technique \\
\hline $\begin{array}{l}\text { Farias-Eisner } 1993 \text { (four } \\
\text { cases) }\end{array}$ & $49-57-59-79$ & $\begin{array}{l}\text { Serous/III (one } \\
\text { with stage IV) }\end{array}$ & Recurrent & $\begin{array}{l}\text { Three were alive and } \\
\text { free for } 3 \text { years, one with } \\
\text { recurrence }\end{array}$ & Open \\
\hline Klinger $1998^{14}$ & 56 & Not available & Not available & Not available & Hand-assisted lap. \\
\hline 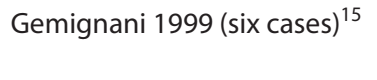 & $58-59-60$ & Epithelial/III & Recurrent & $\begin{array}{l}\text { Free for a median of } \\
25 \text { months }\end{array}$ & 5 open, 1 lap. assisted \\
\hline Ushijima $1999^{16}$ & Not available & Not available & Recurrent & Liver mets & Open \\
\hline Yano $2002^{17}$ & 38 & Serous/IIlc & Recurrence & Not available & Hand-assisted lap \\
\hline Koh $2004^{18}$ & 29 & $\begin{array}{l}\text { Mucinous ( } \mathrm{Hx} \text {. of } \\
\text { borderline tumor) }\end{array}$ & Recurrence & Recurrence after 3 years & Open \\
\hline Tserkezoglou $2005^{19}$ & 53 & Serous/IIlb & Recurrence & $\begin{array}{l}\text { Disease free for } \\
20 \text { months }\end{array}$ & Open \\
\hline Furukawa $2006^{20}$ & 59 & Serous/lc & Recurrence & $\begin{array}{l}\text { Disease free for } \\
60 \text { months }\end{array}$ & Open \\
\hline Otrock $2006^{9}$ & 59 & Serous/lla & Recurrence & $\begin{array}{l}\text { Disease free for } \\
8 \text { months after } \\
\text { chemotherapy }\end{array}$ & Laparoscopic \\
\hline Alloni 2008 (two cases) $^{21}$ & 51,53 & Serous/IIlc & Recurrence & $\begin{array}{l}\text { Free } 7 \text { months after } \\
\text { operation }\end{array}$ & Laparoscopic-assisted open \\
\hline Yoshioka $2008^{22}$ & 61 & Not available & Recurrence & Disease free for 10 years & Open pancreatosplenectomy \\
\hline Ghani $2010^{7}$ & 85 & Mucinous/IV & Primary & Not available & Open \\
\hline Olsen $2011^{23}$ & 72 & Carcinosarcoma & Recurrence & Not available & Open + partial gastrectomy \\
\hline Lv $2014^{13}$ & 53 & Clear cell/IV & Primary & Not available & Open \\
\hline Yasuda $2018^{24}$ & 62 & Endometrioid/IIlc & Recurrent & Not available & Laparoscopic \\
\hline
\end{tabular}




\section{Conclusion}

Splenic metastasis from ovarian cancer is relatively rare. Thorough follow-up of ovarian cancer cases including careful clinical examination, $\mathrm{CT}$, and tumor markers assessment when clinically indicated can early detect any recurrence events even isolated splenic recurrence. Splenectomy as a secondary cytoreductive surgery is a safe procedure that leads to achieving improved both survival and quality of life.

\section{Clinical Significance}

Although being rare, parenchymal splenic metastasis should be suspected in advanced stage ovarian cancer. Splenectomy aiming at secondary cytoreduction is the cornerstone of management in resectable disease.

\section{Author Contribution}

Mohammad Zuhdy wrote the manuscript and assisted in operative procedure. Khaled Gaballa revised the manuscript. Omar Hamdy revised and formatted the manuscript. Reham Alghandour did the first case presentation writing and patients oncological follow-up. Mohamed G Elmadawy did the second case presentation writing and assistant in operative procedure. Yasmin N Laimon did the pathological diagnosis and interpretation. Gehad A Saleh did the radiological diagnosis and interpretation. Mahmoud M Saleh did the patient follow-up and manuscript reformatting. Dr Amr Hosam is the main operator who was also responsible for manuscript revision and final approval.

\section{Informed Consent}

An informed consent was taken from both cases.

\section{Ethical Approval}

The type of manuscript is a case report which does not need an Ethical Committee approval.

\section{References}

1. Bray F, Ferlay J, Soerjomataram I, et al. Global cancer statistics 2018: GLOBOCAN estimates of incidence and mortality worldwide for 36 cancers in 185 countries. CA Cancer J Clin 2018;68(6):394-424. DOI: 10.3322/caac. 21492 .

2. Eisenkop SM, Spirtos NM, Friedman RL, et al. Relative influences of tumor volume before surgery and the cytoreductive outcome on survival for patients with advanced ovarian cancer: a prospective study. Gynecol Oncol 2003;90(2):390-396. DOI: 10.1016/S00908258(03)00278-6.

3. Berge T. Splenic metastases: frequencies and patterns. APMIS 1974;82(4):499-506.

4. Kraus MD, Fleming MD, Vonderheide $\mathrm{RH}$. The spleen as a diagnostic specimen: a review of 10 years' experience at two tertiary care institutions. Cancer 2001;91(11):2001-2009. DOI: 10.1002/1097-0142(20010601)91:11<2001::AID-CNCR1225>3.0.CO;2-3.

5. Fleming GRB, Seidma J, Zaino R, et al. Epithelial ovarian cancer. In: Barakat RR, Markman M, Randall M (ed.) Principles and Practice of
Gynecologic Oncology. Wolters Kluwer Health/Lippincott Williams \& Wilkins; 2009. pp. 763-836.

6. Magtibay PM, Adams PB, Silverman MB, et al. Splenectomy as part of cytoreductive surgery in ovarian cancer. Gynecol Oncol 2006;102(2):369-374. DOI: 10.1016/j.ygyno.2006.03.028.

7. Ghani AA, Hashmi ZA, Chase DM, et al. Intraparenchymal metastases to the spleen from ovarian cancer: a case report. J Med Case Rep 2010;4(1):30. DOI: 10.1186/1752-1947-4-30.

8. Farias-Eisner R, Braly P, Berek JS. Solitary recurrent metastasis of epithelial ovarian cancer in the spleen. Gynecol Oncol 1993;48(3): 338-341. DOI: 10.1006/gyno.1993.1059.

9. Otrock Z, Seoud M, Khalifeh M, et al. Laparoscopic splenectomy for isolated parenchymal splenic metastasis of ovarian cancer. Int J Gynecol Cancer 2006;16(5):1933-1935. DOI: 10.1111/j.15251438.2006.00662.x.

10. Lam K, Tang V. Metastatic tumors to the spleen: a 25-year clinicopathologic study. Arch Pathol Lab Med 2000;124(4):526-530.

11. Kataoka A, Nishida T, Sugiyama T, et al. A study on the distribution of metastases at autopsy in 70 patients with ovarian cancer. Nihon Shokakibyo Gakkai Zasshi 1994;46(4):337-344.

12. Compérat E, Bardier-Dupas A, Camparo P, et al. Splenic metastases: clinicopathologic presentation, differential diagnosis, and pathogenesis. Arch Pathol Lab Med 2007;131(6):965-969.

13. Lv M, Li Y, Luo $C$, et al. Splenic metastasis of ovarian clear cell adenocarcinoma: a case report and review of the literature. Exp Ther Med 2014;7(4):982-986. DOI: 10.3892/etm.2014.1500.

14. Klinger $P$, Smith SL, Abendstein BJ, et al. Hand-assisted laparoscopic splenectomy for isolated splenic metastasis from an ovarian carcinoma: a case report with review of the literature. Surg Laparo Endo Per 1998;8(1):49-54. DOI: 10.1097/00019509-199802000-00012.

15. Gemignani $M, C h i D$, Gurin C, et al. Splenectomy in recurrent epithelial ovarian cancer. Gynecol Oncol 1999;72(3):407-410. DOI: 10.1006/ gyno.1998.5141.

16. Ushijima K, Nishida T, Okura N, et al. Solitary splenic recurrence of ovarian cancer: case report and review of the literature. Arch Gynecol Obstet 1999;263(1-2):79-81. DOI: 10.1007/s004040050268.

17. Yano $H$, Iwazawa $T$, Kinuta $M$, et al. Solitary splenic metastasis from ovarian cancer successfully treated by hand-assisted laparoscopic splenectomy: report of a case. Surg Today 2002;32(8):750-752. DOI: 10.1007/s005950200142.

18. Koh YS, Kim JC, Cho CK. Splenectomy for solitary splenic metastasis of ovarian cancer. BMC Cancer 2004;4(1):96. DOI: 10.1186/1471-24074-96.

19. Tserkezoglou A, Kontou S, Hatjieleftheriou G, et al. Solitary parenchymal splenic recurrence of ovarian adenocarcinoma: a case report and review of the literature. Anticancer Res 2005;25(2B):1471-1476.

20. Furukawa N. Solitary splenic metastasis of ovarian cancer. Arch Gynecol Obstet 2007;275(6):499-502. DOI: 10.1007/s00404-006-0274-4.

21. Alloni R, Garberini A, Caputo D, et al. Solitary splenic metastasis of ovarian carcinoma: report of two cases. Surg Today 2008;38(12): 1144-1147. DOI: 10.1007/s00595-007-3747-6.

22. Yoshioka R, Okabayashi T, Nishimori I, et al. A long-survived case with solitary splenic metastasis from ovarian carcinoma. Surg Technol Int 2008;17:192-194.

23. Olsen $A B$, Pargman $S$, Gillespie $T$. Solitary splenic metastasis from ovarian carcinosarcoma: a case report. J Med Case Rep 2011;5(1):56. DOI: 10.1186/1752-1947-5-56.

24. Yasuda K, Yoshimura T, Kitade H, et al. Laparoscopic splenectomy for solitary splenic metastasis in a patient with ovarian cancer with a long disease-free interval: a case report. J Med Case Rep 2018;12(1):132. DOI: $10.1186 / \mathrm{s} 13256-018-1673-4$. 